\title{
Erratum to: Curricular Influences on Female Afterschool Facilitators' Computer Science Interests and Career Choices
}

\author{
Melissa Koch ${ }^{1}$ • Torie Gorges ${ }^{1}$
}

Published online: 2 November 2016

(C) Springer Science+Business Media New York 2016

Erratum to: J Sci Educ Technol

DOI: $10.1007 / \mathbf{s} 10956-016-9636-2$

The original version of this article unfortunately contained a mistake.

Acknowledgments should Read:

This material is based upon work supported in part by the National Science Foundation under Grant No. 1,339,181. Any opinions, findings, and conclusions or recommendations expressed in this material are those of the author(s) and do not necessarily reflect the views of the National Science Foundation.

This article was actually intended for the special issue: ITEST. However, inadvertently, it has been published in the regular issue of Volume 25 Issue 5 (October 2016), pp. 782-794.

The online version of the original article can be found at http://dx.doi. org/10.1007/s10956-016-9636-2

Melissa Koch

mel@melissakoch.com

1 SRI International, Menlo Park, CA, USA 